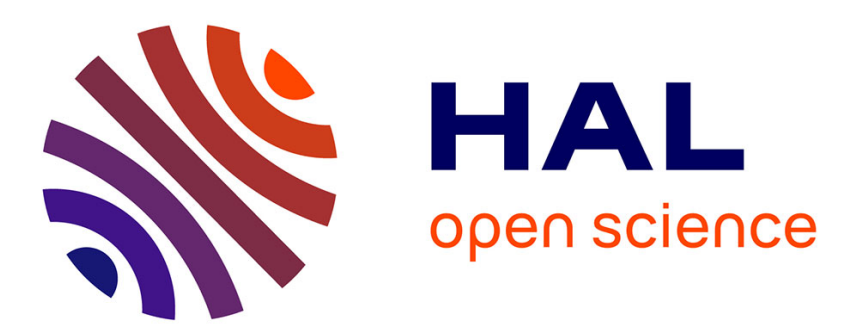

\title{
Morpho-granular approach to characterize harbour sediments and their agglomeration/dispersion behaviour Fanny Coulon, Nathalie Azema
}

\section{To cite this version:}

Fanny Coulon, Nathalie Azema. Morpho-granular approach to characterize harbour sediments and their agglomeration/dispersion behaviour. Powder Technology, 2015, 275, pp.139-151. 10.1016/j.powtec.2015.01.021 . hal-02914244

\section{HAL Id: hal-02914244 \\ https://hal.science/hal-02914244}

Submitted on 1 Jun 2021

HAL is a multi-disciplinary open access archive for the deposit and dissemination of scientific research documents, whether they are published or not. The documents may come from teaching and research institutions in France or abroad, or from public or private research centers.
L'archive ouverte pluridisciplinaire HAL, est destinée au dépôt et à la diffusion de documents scientifiques de niveau recherche, publiés ou non, émanant des établissements d'enseignement et de recherche français ou étrangers, des laboratoires publics ou privés. 


\title{
Morpho-granular approach to characterize harbour sediments and their agglomeration/dispersion behaviour
}

\author{
Fanny Coulon, Nathalie Azéma* \\ Centre des Matériaux des Mines d'Alès (C2MA), Ecole des mines d'Alès, 6 Avenue de Clavières, 30319 Alès Cedex, France
}

\begin{abstract}
A B S T R A C T
An exhaustive physico-chemical and morpho-granular characterization of sediments collected in Port-Camargue harbour was investigated to improve marine sediment knowledge and to study inter-particle phenomena (granular properties and agglomeration/dispersion state). In the context of dredging framework, these phenomena could lead to disperse pollution in water column through chemical mobilization (dissolution or sorption phenomena) and/or physical mobilization (dispersion/agglomeration phenomena). Moreover they could disturb sedimentation behaviour which may lead to take pollution away from harbour. This work was focused on particle solid phase of sediment. Granular aspects were jointly studied with laser granulometry, electrophoresis measurements and Scanning Electron Microscopy (SEM). Chemical and mineralogical properties were mainly characterized with X-ray Diffraction (XRD) and Scanning Electron Microscopy with Energy Dispersive X-ray spectroscopy (SEM-EDX). These analyses were performed on bulk sediments and size fractioned sediments $(<20 \mu \mathrm{m}$; 20-40 $\mu \mathrm{m} ; 40-63 \mu \mathrm{m} ; 63-80 \mu \mathrm{m} ;>80 \mu \mathrm{m})$. Results showed that sediments can be differentiated by their granular properties (different in size distribution, shape and inter-particle interactions). A classification was proposed in function of their particle size distribution and silt percentage (very low proportion of clay is neglected): silty, silty sand and sand sediments. Furthermore, due to the presence of agglomeration/aggregation and dispersion behaviours, a morpho-granular approach was used to identify different types of agglomerates/aggregates. To minimize the impact of these phenomena on separation process of size fraction, often needed to investigate these systems, an optimized method was developed for sieving with a mechanical agitation and rinsing.

This experimental work could therefore supplement and enrich the chemical and biological approaches of marine sediments observed in the more conventional pollution mobilization studies.
\end{abstract}

Keywords:

Agglomeration

Dispersion

Sediment

Characterization

Classification

Separation method

\section{Introduction}

Dredging of marine sediments is required in many ports, to deepen and to maintain depth of the shipping channel. However, dredging activities, and especially the release of sediments during dredging and the disposal of dredged material, can impact marine habitats [1-5]. Among other things, dredging and marine disposal activities can contribute to remobilize fine sediment-associated contaminants [6,7].

Sediments in estuaries and harbour areas are complex mixtures composed of solid and liquid phases with different characteristics and compositions. The liquid phase is predominately water with ions and molecules such as organic matter [8]. The solid phase consists of granular inorganic and organic materials that present many physical and geochemical properties (particle size distribution, water content, cohesive nature, mineralogical and geochemical compositions), responsible for biochemical and physicochemical interactions such as agglomeration/

* Corresponding author at: Ecole des mines d'Alès, 6 Avenue de Clavières, 30319 Alès Cedex, France. Tel.: +334667853 56; fax: + 33466785365 .

E-mail address: nathalie.azema@mines-ales.fr (N. Azéma). dispersion (weak physical bond), aggregation (strong chemical bond), dissolution/precipitation and sorption phenomena [9-11].

Moreover, these interactions can lead to trap organic or metallic contaminants in fine fraction $(<80 \mu \mathrm{m})$ of sediments [12-16]. Generally literature presents studies on adsorption/desorption and precipitation/ dissolution phenomena that contribute to pollution mobilization $[1,9,10,17]$. But dispersion/agglomeration phenomena can also mobilize molecule or particle pollutants adsorbed or agglomerated on mineral fractions (Fig. 1). Therefore pollutants can be transferred between granulometric fractions (smaller or bigger) and, for that reason, to be transported or to settle.

In dredging framework, agglomeration/dispersion interactions could therefore lead to disperse pollution in water column which could lead to transport it outside the harbour, and/or to impact particle settling at the bottom of the harbour. Then, the aim of this work is to have a better knowledge of solid fraction of sediment, and to investigate agglomeration/dispersion state of harbour sediment particles. An exhaustive characterization of physicochemical and granular aspects has been carried out on bulk and size fractioned sediments. Data published in the literature are focused on chemical distribution of contaminants, and biological or physicochemical properties of marine sediments. 


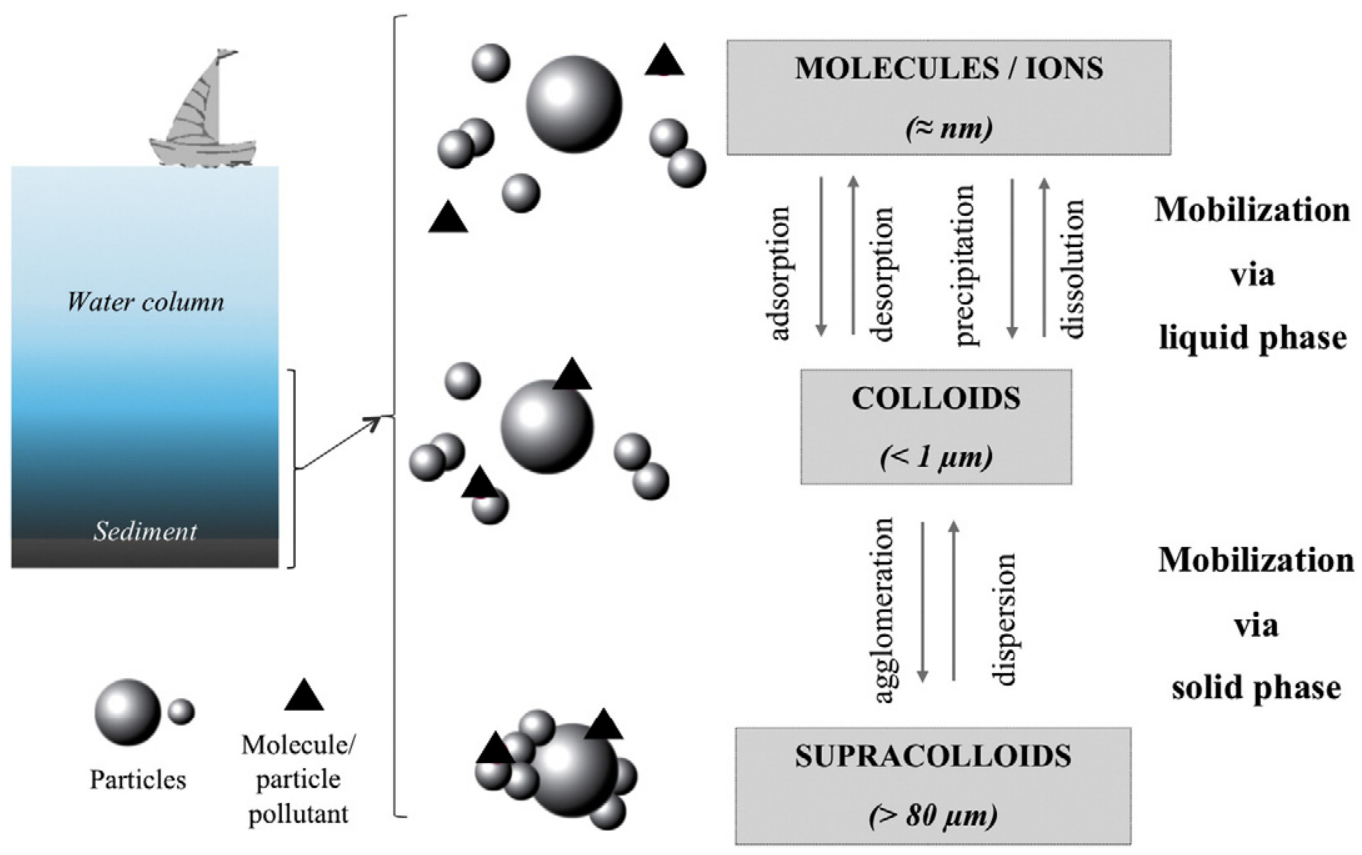

Fig. 1. Particle interactions and pollutant mobilizations.

Some other studies introduce sediment/contaminant interactions in various solid fraction phases (organic and mineral) and the liquid phase (water and pore water) [7,18-23]. But few studies carry out morphogranulometric characterization of sediment particles and agglomeration/dispersion behaviours.

The first part of this paper concerns granular and physicochemical characterization of bulk sediments. Firstly, chemical and mineralogical composition and physicochemical characteristics were determined. Then population identification and granular characteristics of particles were discussed in detail. The granulometric distributions can also permit classification of the sediments, according to standard US Department of Agriculture Soil Textural Classification Triangle [24]. Finally, a study has been achieved combining laser granulometry, ultra-sonification and zeta potential measurements in order to characterize agglomeration/dispersion state of sediments and to identify the different agglomerate/aggregate types. The second part is focused on characterization of size fractioned sediments $(<20 \mu \mathrm{m} ; 20-40 \mu \mathrm{m}$; 40-63 $\mu \mathrm{m}$; $63-80 \mu \mathrm{m} ; 80-100 \mu \mathrm{m})$ that requires an optimized granulometric separation despite agglomeration/dispersion phenomena existence and their impact on separation process.

\section{Material and methods}

\subsection{Field sites and sampling}

Study area is the Port-Camargue harbour localized in South France, in the Gulf of Lion that is a wide embayment of Mediterranean coastline. This is one of the largest marinas in Europe and is close to Natura 2000 sites that are protected nature reserves. It has not been dredged since 1969 (date of its construction) because of a low sedimentation rate, a characteristic of Mediterranean Sea [25]. Several sediment samples were taken into the harbour in order to observe and to characterize sediments by descriptive criteria (i.e. texture, structure, and colour related to rate of mud). But only three of them have been chosen for this work (Fig. 2); one is located in the outer-harbour zone (Sampling 1) with a muddy material, one is situated in an old technical zone

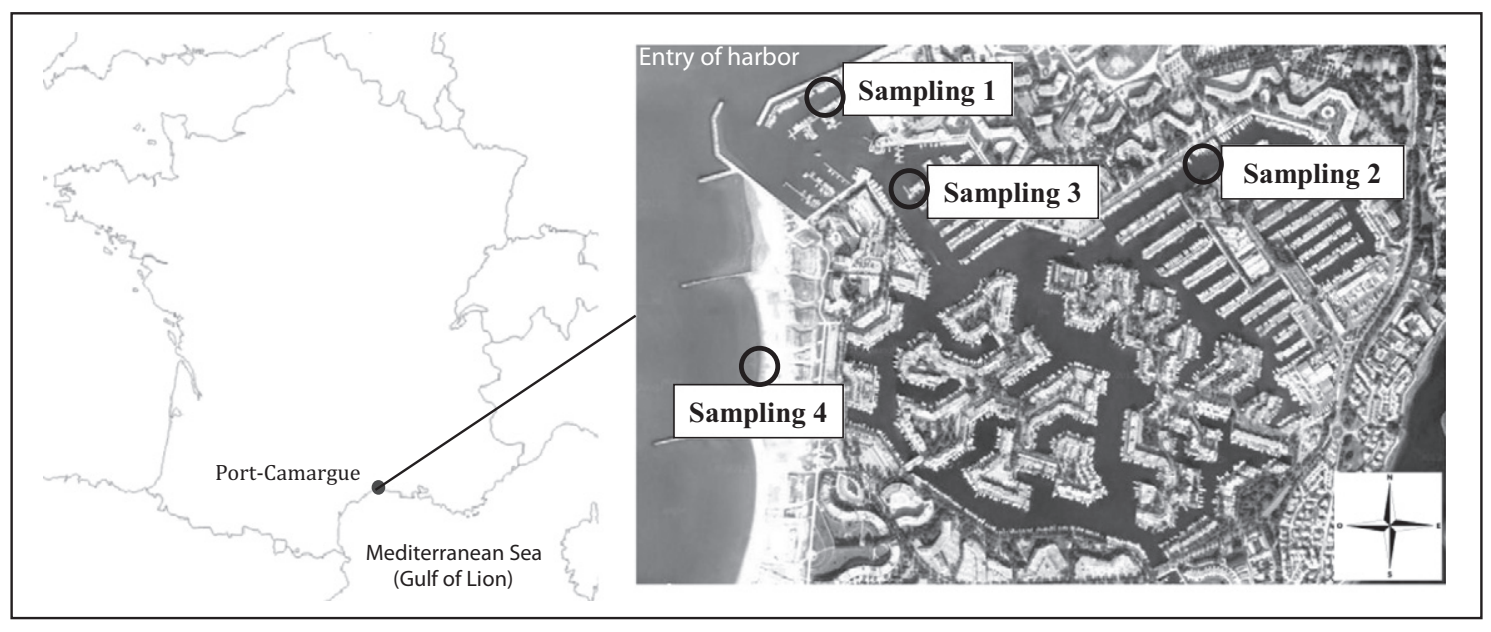

Fig. 2. Locations of sampling stations. 
(Sampling 2) characterized by a sediment with a sandy-muddy texture, and another is located at the harbour entrance zone (Sampling 3 ) with a sandy material. An additional sample of beach sand was also collected as reference (Sampling 4). Sediment samples were collected with a core sampler (10 to $50 \mathrm{~cm}$ depth in function of the sediment structure and $7 \mathrm{~cm}$ diameter). Beach sand sample was directly collected with a small shovel. All samples were transferred into closed glass containers and were kept at $4{ }^{\circ} \mathrm{C}$.

\subsection{Analysis methods}

\subsubsection{Granular characterization methods}

Concerning granular analyses, sediment samples were mechanically homogenized with demineralised water in order to obtained a suspension with a ratio 1:10 (1 volume of sediment to 10 volumes of water). This ratio was chosen in order to reproduce the dredging process conditions. Mechanical stirring time is $15 \mathrm{~min}$. Size fractioned sediments were obtained by wet sieving of sediment suspensions through $80 \mu \mathrm{m}, 63 \mu \mathrm{m}, 40 \mu \mathrm{m}$ and $20 \mu \mathrm{m}$ meshes according to Renard series (NF X11-504; 1975). This fractionation method will be discussed later in this paper (Section 3.2.1).

Granulometric distributions were determined in demineralised water on a few milligrams of suspension. The instrument used is a Laser Granulometer LS 13320 from Beckman-Coulter Company. Particle size distribution is obtained by scattering of monochromatic light with a wavelength of $780 \mathrm{~nm}$ diffracted and transmitted through the suspension. The chosen optical model $(\mathrm{n}=1.57+0.3 \mathrm{i})$ computes the flux pattern into a particle size distribution in the range of 0.017 to
Sampling 1
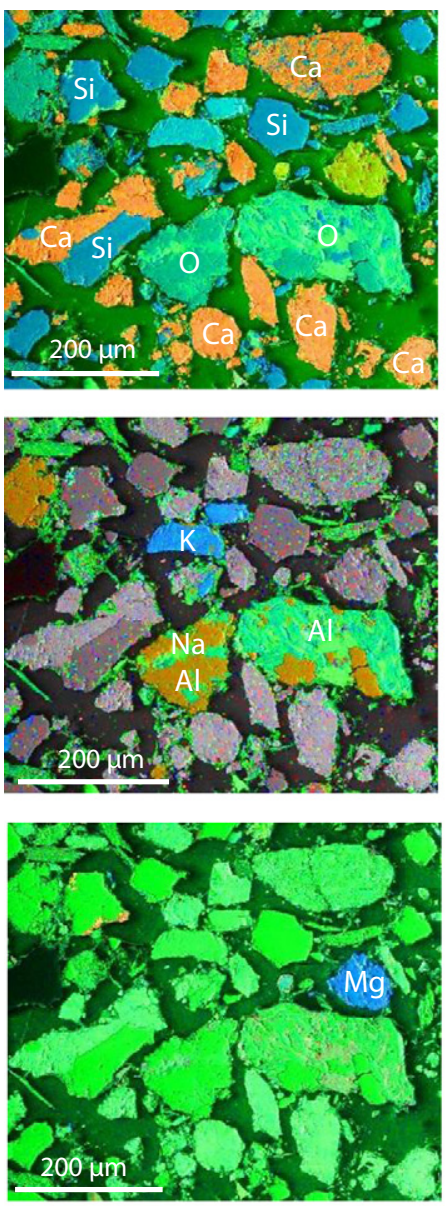

Sampling 3
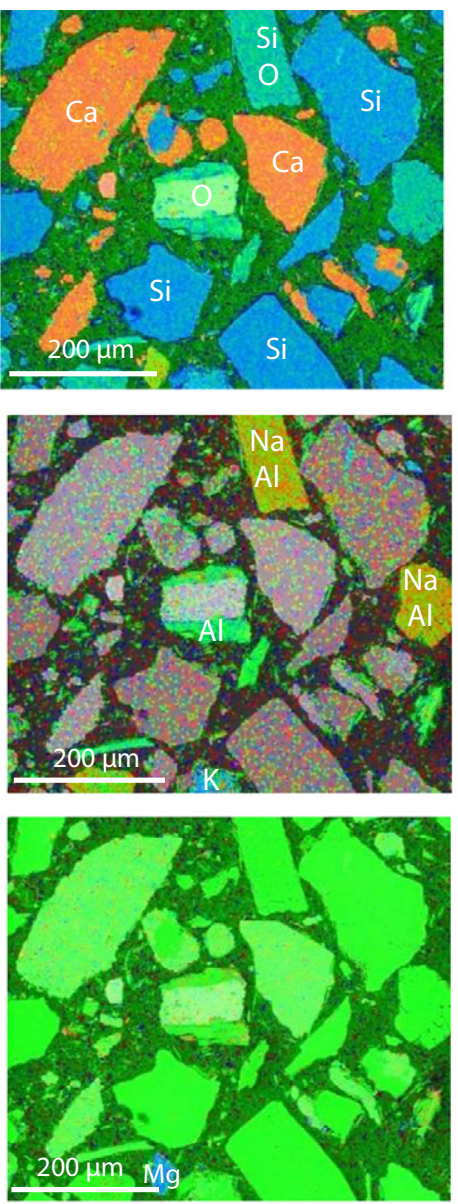

Sampling 2
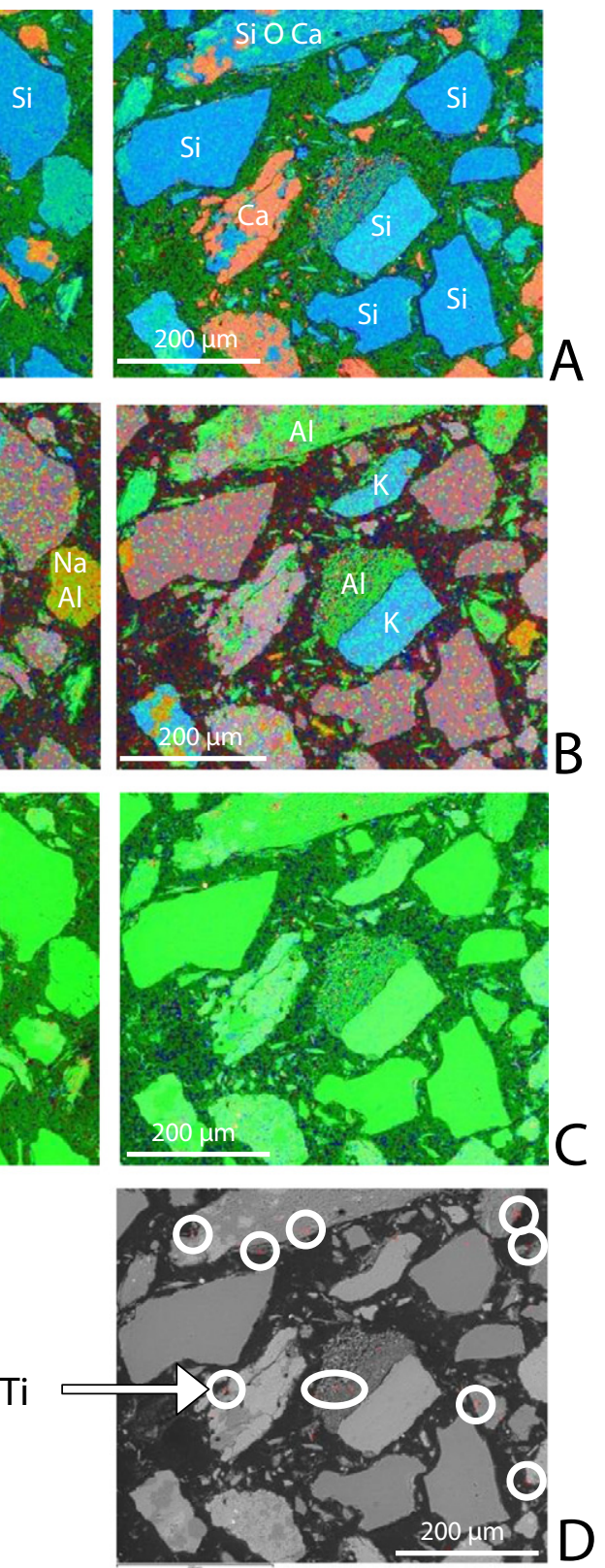

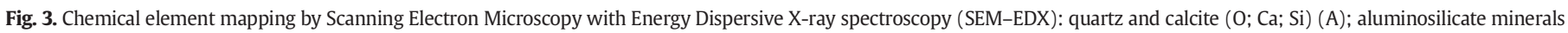
(Al; Na; K) (B); oxides (Fe; Mg) (C); Ti (D). 
$2000 \mu \mathrm{m}$ of particle diameters (we note that particles are considered as spherical objects). Each analysis is at least reproduced twice. Repeatability of analysis indicated particle size modes up to within $\pm 2 \mu \mathrm{m}$ and reproducibility shows a maximum relative standard deviation (RSD) to 10\% (due to sample heterogeneity).

An Environmental Scanning Electron Microscope with Energy Dispersive X-ray spectroscopy (SEM-EDX) (Quanta 200 FEG) from the FEI Company was used to observe particles contained in the sediment suspensions. A specific sample preparation technique [26] was used to observe: size, shape (morphology) and surface of particles and agglomeration/aggregation state.

Specific surface areas were measured by nitrogen adsorption (BET method) using an SA3100 surface area analyser from the BeckmanCoulter Company. For this technique, it was necessary to dry sediment samples at $40{ }^{\circ} \mathrm{C}$ for $72 \mathrm{~h}$.

\subsubsection{Mineralogical and chemical analysis methods}

The mineralogical analyses were performed by $\mathrm{X}$-ray diffractometry using a Brüker AXS diffractometer with $\mathrm{Cu} K \alpha$ radiation $(\lambda 1,54 \AA)$. The sediment samples were also dried at $40^{\circ} \mathrm{C}$ for $72 \mathrm{~h}$ and roughly grinded with a mortar before analysis. Chemical element mappings were also obtained with SEM-EDX presented in Section 2.2.1. This analysis permits obtaining information on elemental chemical composition of particles. To achieve this, sediment samples were mixed in an epoxy resin-hardener system (Araldite D E501 by ESCIL) and polished under water with several discs (320-600-900-1000-4000 grains/ $\left.\mathrm{cm}^{2}\right)$ at a maximum speed of $100 \mathrm{rpm}$. Polished section was rinsed with ethanol before analysis.

\subsubsection{Physicochemical analysis methods}

Followed physicochemical parameters were determined: $\mathrm{pH}$, water content, density and mass percentage fraction. The $\mathrm{pH}$ of bulk sediment was measured in situ with a glass $\mathrm{pH}$ electrode during sampling with seawater. Density of sediments dried at $40{ }^{\circ} \mathrm{C}$ for $72 \mathrm{~h}$ was obtained using a pycnometer AccuPyc 1330 from the Micromeritics Company. Water content and mass percent fraction were determined by difference in mass weighed before and after drying at $40{ }^{\circ} \mathrm{C}$ for $72 \mathrm{~h}$. Mass percent for each sediment granular fractions was obtained by wet sieving of sediment suspensions according to Renard series.

\subsubsection{Zeta potential measurement}

One of the main parameters to assess electrostatic particle interactions is zeta potential [27]. Zeta potential of diluted sediment suspensions was determined in demineralised water (one volume of sediment to 100 volumes of water). Before each analysis, ionic conductivity of diluted suspension was verified in order to not exceed $8 \mathrm{mS}$. This analytical condition is necessary to realize electrophoretic measurements with a Zetasizer Nano-ZS instrument (Malvern). This instrument measures electrophoretic mobility and calculates zeta potential value from Smoluchowski equation [27]:

$\mathrm{U}_{\mathrm{E}}=\varepsilon_{\mathrm{r}} \varepsilon_{0} \frac{\zeta}{\eta}$

where $U_{E}$ is electrophoretic mobility (velocity divided by field strength) $\left(\mathrm{m}^{2} \mathrm{~V}^{-1} \mathrm{~s}^{-1}\right)$ and $\zeta$, zeta potential $(\mathrm{V})$. For water at $25^{\circ} \mathrm{C}$, $\varepsilon_{\mathrm{r}}$ is relative permittivity of the medium $\left(78.6 \mathrm{~F} \cdot \mathrm{m}^{-1}\right), \varepsilon_{0}$ permittivity of free space $\left(8.85 \times 10^{-12} \mathrm{~F} \cdot \mathrm{m}^{-1}\right)$ and $\eta$ bulk liquid viscosity (for water, $\left.9.9 \times 10^{-4} \mathrm{~Pa} \cdot \mathrm{s}\right):$

$\zeta=1.282 \times 10^{6} \times \mathrm{U}_{\mathrm{E}}$.

Measurements were conducted at ambient temperature. An instrumental standard error is associated to each measure of zeta potential Despite of it, triplicate measurements were conducted for many samples to check reproducibility of the results.

At high absolute (negative or positive) value of zeta potential, dispersion is considered as stable. Indeed, electrostatic repulsions prevent agglomeration of dispersed particles. When absolute value of potential is low $(<10 \mathrm{mV})$, agglomeration is favoured. Below $30 \mathrm{mV}$, dispersion exhibits incipient instability. Absolute value of $30 \mathrm{mV}$ is generally the limit between stable and unstable suspensions [28,29].

\section{Results and discussions}

\subsection{Bulk sediment characterization}

\subsubsection{Chemical and mineralogical composition}

An elementary chemical analysis and a mapping were performed on sample polished surface (surface: $0.42 \mathrm{~mm}^{2}$ ) (Fig. 3). Sediments were

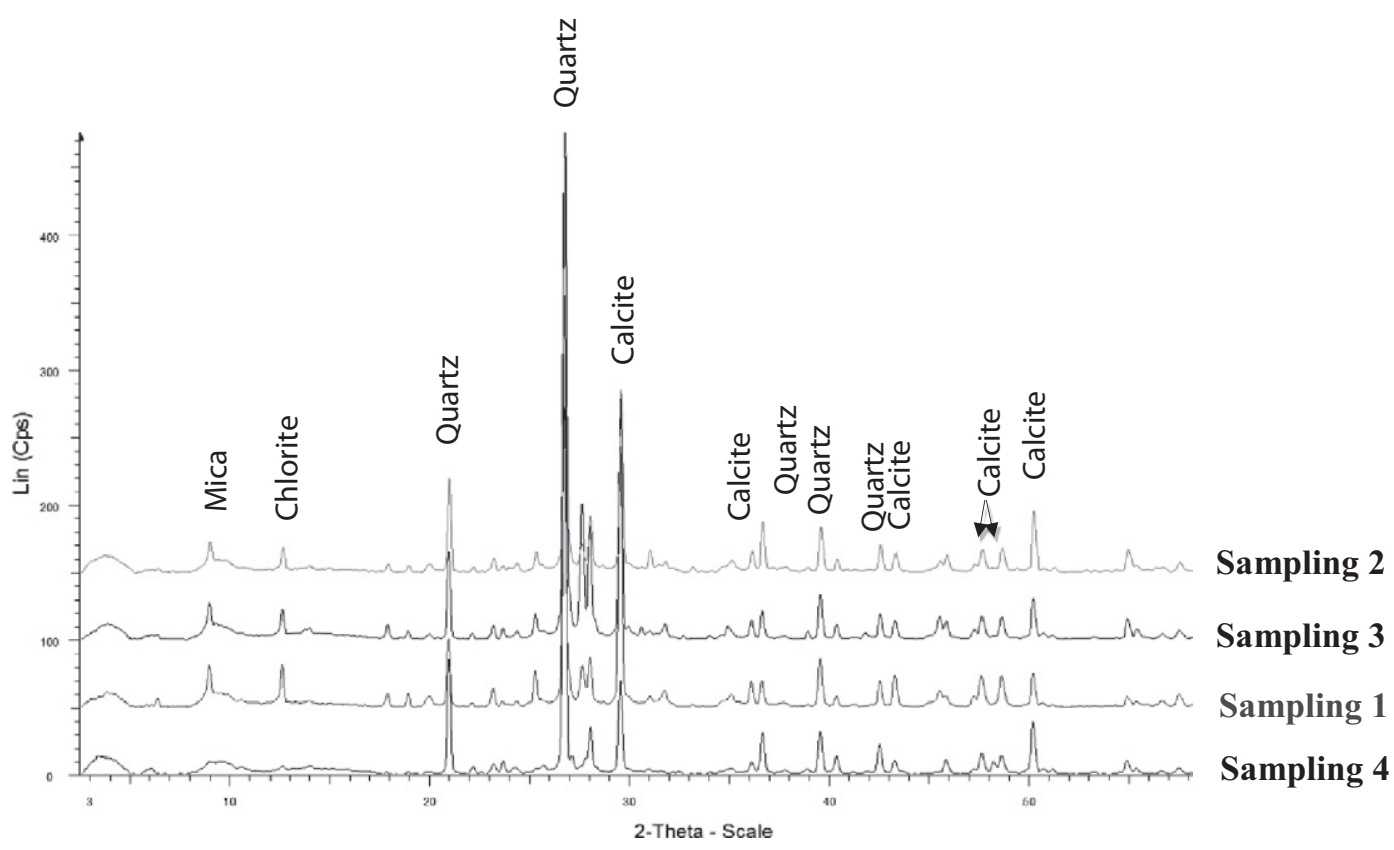

Fig. 4. X-ray diffractograms of Port-Camargue sediments. 

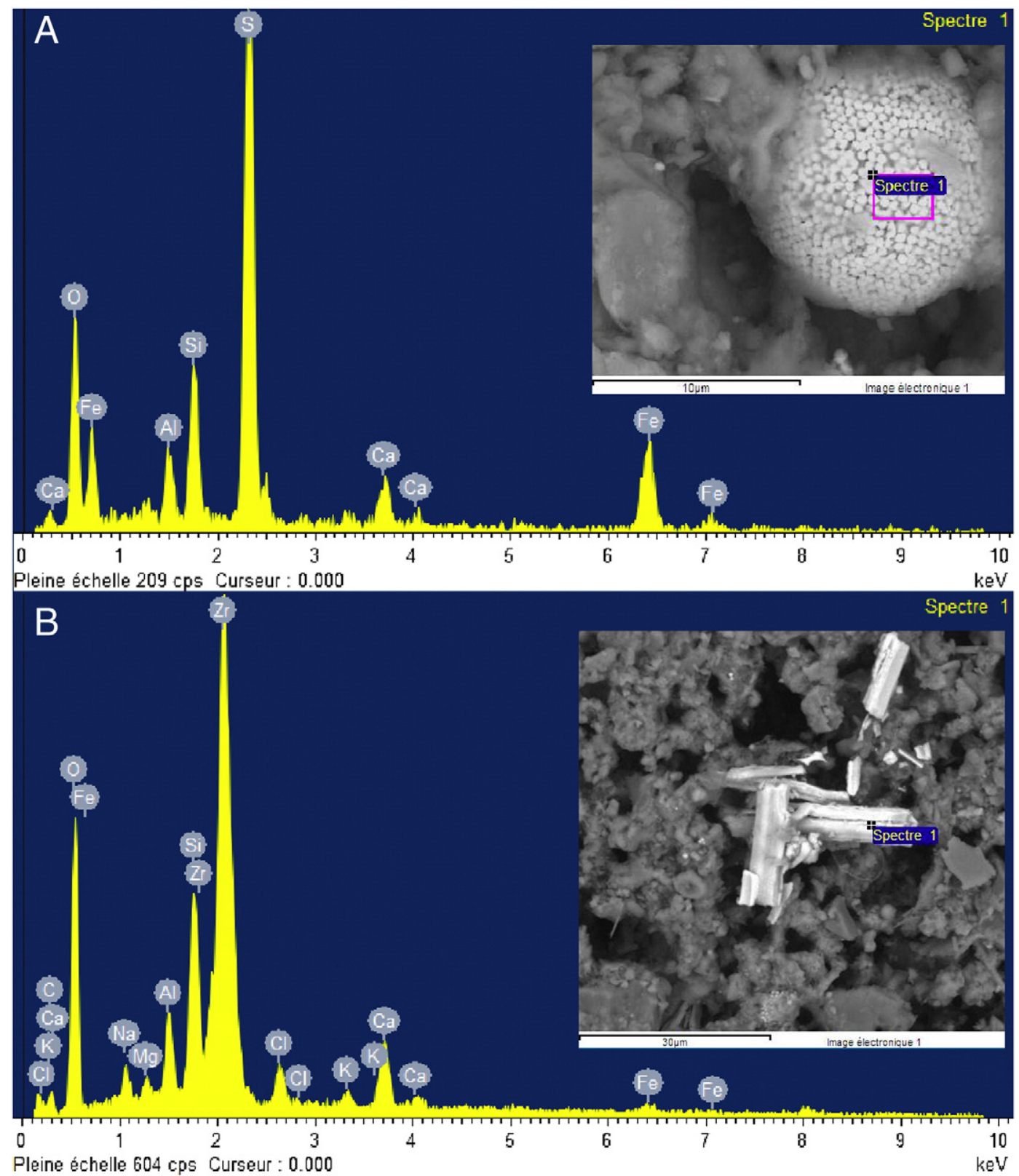

Fig. 5. Scanning electron micrographs with Energy Dispersive X-ray spectroscopy (SEM-EDX): A. framboidal pyrite in Sampling 1; B. Zr particle in Sampling 2.

also characterized by X-ray Diffraction (Fig. 4). Studied sediments have relatively similar mineralogical and elementary chemical compositions and are principally composed of silicates, aluminosilicates and calcite. For example, quartz $\left(\mathrm{SiO}_{2}\right)$ and calcite $\left(\mathrm{CaCO}_{3}\right)$ are showed in Fig. $3 \mathrm{~A}$, feldspars $\left(\mathrm{Na}\left(\mathrm{AlSi}_{2} \mathrm{O}_{8}\right)-\mathrm{K}\left(\mathrm{AlSi}_{2} \mathrm{O}_{8}\right)\right)$ in Fig. 3B, while the elements $\mathrm{Mg}$, $\mathrm{Fe}, \mathrm{K}$ and $\mathrm{Ti}$ are occurring in relatively small quantities in Fig. $3 \mathrm{C}$ and D. Therefore we can suppose that the Port-Camargue sediments are made up of biogenous materials, derived from hard parts of organisms (i.e. calcite) and lithogenous materials, coming from land by erosion of rocks (i.e. quartz and feldspars) [30]. This origin will condition shape particle as will be discussed in Section 3.1.4. Literature on this subject indicates that major chemical elements identified in marine sediments are $\mathrm{Ca}, \mathrm{Si}, \mathrm{O}$ (i.e. quartz, carbonates) and in lower proportion $\mathrm{Al}, \mathrm{Fe}, \mathrm{Ti}$ and $\mathrm{Cu}[23,31]$. Si, Al and Fe are dominant elements in terrigenous sediments. Sediments in Gulf of Lion (France) are mainly composed of Al, $\mathrm{Ca}, \mathrm{Fe}, \mathrm{P}$ and $\mathrm{Ti}$ [20]. These elements are almost all elements identified in Port-Camargue sediments.

Furthermore, EDX analysis shows that hexagonal particles observed are mainly composed of S and Fe (Fig. 5A). These agglomerated particles are called framboidal pyrites and are obtained by reaction of hydrogen sulfide with ferrous iron. Pyrite is commonly found in coastal, marine and estuarine anoxic sediments as well as in argillaceous marine, lacustrine and salt marsh sediments [32,33]. Acicular particles are also observed, especially in mud fraction. These particles are composed of Ti or Zr (Fig. 5B).

\subsubsection{Physicochemical characteristics}

Physicochemical characteristics of studied sediments are listed in Table 1 . Sediment $\mathrm{pH}$ is an important value that can influence mineral

Table 1

Physico-chemical characteristics of sediments investigated in Port-Camargue.

\begin{tabular}{llll}
\hline Sediment & $\mathrm{pH}$ & Density & Water content $(\%)$ \\
\hline Sampling 1 (muddy) & 8.4 & 2.69 & 43 \\
Sampling 2 (sandy-muddy) & 8.3 & 2.68 & 57 \\
Sampling 3 (sand) & 8.3 & 2.69 & 33 \\
Sampling 4 (sand) & $/$ & 2.67 & 31
\end{tabular}


Table 2

Granular characteristics of sediments investigated in Port-Camargue.

\begin{tabular}{|c|c|c|c|}
\hline Sediment & BET specific area $\left(\mathrm{m}^{2} \cdot \mathrm{g}^{-1}\right)$ & Granulometry specific area $\left(\mathrm{m}^{2} \cdot \mathrm{mL}^{-1}\right)$ & Particle size range $d_{\max }-d_{\min }(\mu \mathrm{m})$ \\
\hline Sampling 1 (muddy) & 4.8 & 1.60 & $300-0.1$ \\
\hline Sampling 2 (sandy-muddy) & 3.5 & 0.56 & $600-0.1$ \\
\hline Sampling 3 (sand) & 2.0 & 0.20 & $600-1$ \\
\hline Sampling 4 (sand) & 0.6 & 0.04 & $600-10$ \\
\hline
\end{tabular}

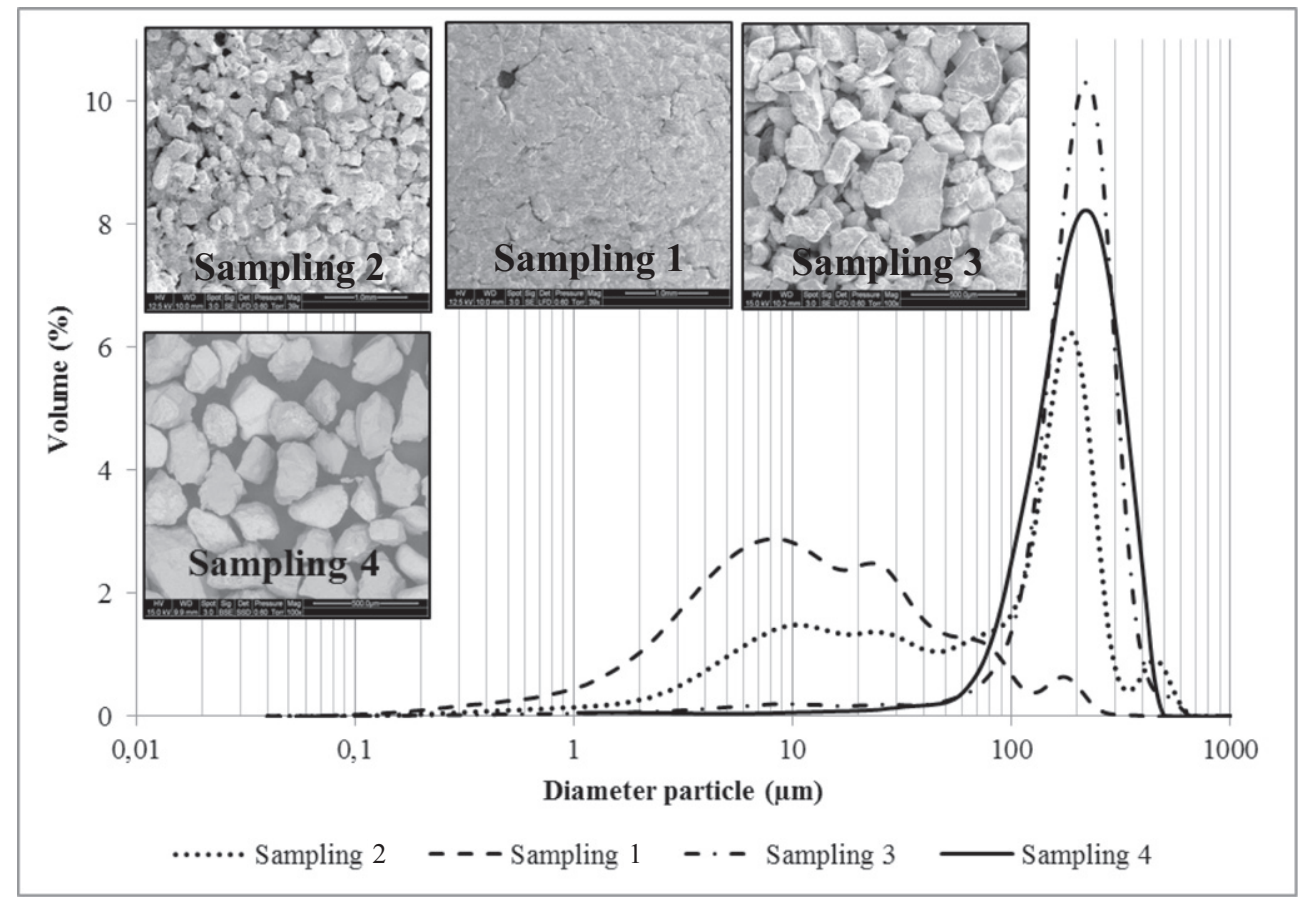

Fig. 6. Particle size distributions and scanning electron micrographs of Port-Camargue sediments.

phase nature, pollution mobilization, and chemical, physicochemical and granular phenomena (i.e. precipitation, desorption, agglomeration...). Sediments had a similar alkaline $\mathrm{pH}$ of 8.3 to 8.4. These values correspond to $\mathrm{pH}$ measured in marine sediments sampled in France [19]. Relative density of dried sediments has a stable value (2.67-2.69) in agreement with X-ray Diffraction results (similar mineralogical composition). Sediments contain between $33 \pm 3 \%$ water for Sampling 4 and $57 \pm 3 \%$ water for Sampling 2.

\subsubsection{Granular characteristics and granulometric classification}

Two of the main granular characteristics of divided material are specific area and particle size distribution. According to Fontaine et al.'s researches [34], sediments with a high specific area have a high adsorptive capacity towards some contaminants. Studied sediments present BET specific areas ranging from 0.6 to $4.8 \mathrm{~m}^{2} \cdot \mathrm{g}^{-1}$ (Table 2). As a comparison, specific areas were also measured by laser granulometry and calculated from spherical particle model. These values ( 0.04 to $1.60 \mathrm{~m}^{2} \mathrm{~mL}^{-1}$ ) are less than BET specific area values. This difference indicates that particle surface is complex either because of agglomeration or surface roughness. Moreover, Tables 1 and 2 show that sediments containing relatively more water have a high BET specific area due to fine particle presence. High water content could indicate a particle agglomerated state that can trap water.

Moreover, Fig. 6 presents particle size distributions of four samples. Particle size distribution of Sampling 3 is mainly monomodal, with a mode value at $200 \mu \mathrm{m}$ as with the sand fraction of beach sand (Sampling 4). This mode corresponds therefore to sand particles in agreement with their low specific area. On the other hand, particle size distribution of Sampling 1 is polydisperse with the widest particle size range from 0.1 to $300 \mu \mathrm{m}$; principal mode is around $8 \mu \mathrm{m}$ and characterizes muddy fraction. The granulometric distribution of Sampling 2 contains also these two modes ( 8 and $200 \mu \mathrm{m}$ ), but in comparable proportion. Furthermore, these analyses allow defining separation diameter between sandy and muddy fractions at $80 \mu \mathrm{m}$. These data are essential to the dredging projects in order to separate what can be reused (sandy fraction) of the rest of sediment that will be principally re-deposited on the harbour bottom. In this work, we focus on the characterization of this last fraction $(<80 \mu \mathrm{m})$.

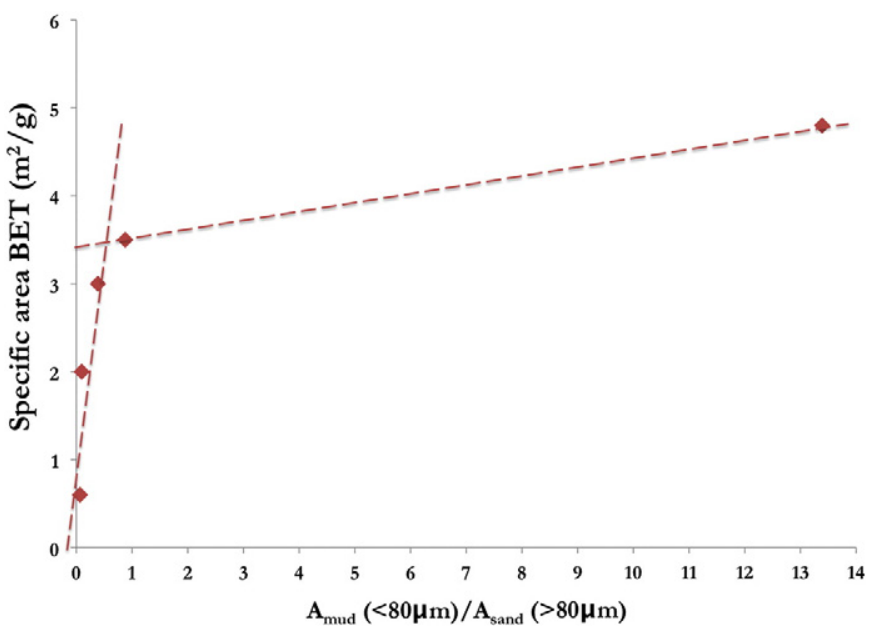

Fig. 7. BET specific area in function of sand/mud area ratio. 
Table 3

Particle-size classes using the USDA soil textural classification and classification in function of \%silt.

\begin{tabular}{|c|c|c|c|c|c|}
\hline Sampling & $\%$ Sand $(>80 \mu \mathrm{m})$ & $\%$ Silt $(2-80 \mu \mathrm{m})$ & $\%$ Clay $(<2 \mu \mathrm{m})$ & USDA classification & \%Silt Classification (S: sand; s: silt) \\
\hline 1 & 6.9 & 83.6 & 9.4 & Clay & Ss84 \\
\hline 2 & 53.3 & 43.7 & 3.0 & Sandy clay loam & Ss 44 \\
\hline 3 & 91.2 & 7.7 & 1.0 & Sand & Ss8 \\
\hline 4 & 92.6 & 5.6 & 0.4 & Sand & Ss6 \\
\hline
\end{tabular}

These granulometric distributions were correlated with BET specific areas determined previously. Areas under the curve were collected for sediment fractions: $<80 \mu \mathrm{m}$ (mud) and $>80 \mu \mathrm{m}$ (sand). An additional sample was analysed in order to obtain enough data to realize Fig. 7 , showing a linear trend between the $A_{\text {mud }} / A_{\text {sand }}$ ratio and BET specific area value when this ratio is below 1 ( 50 vol.\% of each fraction). In this case, we observe a significant impact of quantity of muddy particles (fine particles) on the BET specific area value, as expected when surface/ volume ratio increases. But when this ratio is higher than 1, we don't explain that there is no influence observed.

Granulometric distributions can also permit classification of sediments. According to standard US Department of Agriculture Soil Textural Classification Triangle, soils can be classified in function of their proportions of sand, silt and clay [24]. In literature, different methods exist for fractioning sediments such as wet sieving, pipette method and sedimentrometry method [35-37]. In this work, we propose to realize textural classification by laser granulometry. Compared to different methods observed in literature, this method is a quick and easy method which does not require any particular preparation and any chemical agent addition. As previously indicated in figure 7, area under the curve was determined for three fractions: $<2 \mu \mathrm{m}$ (clay), 2 to $80 \mu \mathrm{m}$ (silt) and $>80 \mu \mathrm{m}$ (sand). The observed areas are expressed in volume percent (Table 3.) and are reported on sediment textural triangle (Fig. 8). The USDA textural classification permitted to identify Sampling 1 as silt, Sampling 2 as silty sand, and Samplings 3 and 4 as sand. These results show that clay fraction can be considered as a negligible component. Another classification was established in function of silt proportion (Table 3): Ss6 (Sand-silt 6\%), Ss8 (Sand-silt 8\%), Ss44 (Sand-silt 44\%) and Ss84 (Sand-silt 84\%). We can note that in a first approximation we will neglect aggregation and/or agglomeration phenomena which can influence the size classification proposed.

\subsubsection{Identification of granular populations}

After textural characterization and classification of sediments, an in-depth identification of particle populations was realized by laser granulometry and Scanning Electron Microscopy (SEM). Knowledge of particle populations permits identification of different particle phases (organic and mineral), and give some information about agglomeration/dispersion state. Generally, morphology, specific area and size of unit and agglomerated/aggregated particles influence global behaviour of sediments [9-11].

The observed sediments present many modular, angular and a few platelet shaped particles of all sizes $(0.04$ to $700 \mu \mathrm{m})$ resulting from the rock erosion and fragmentation as it has been mentioned in Section 3.1.1. In the case of sand (Ss6 and Ss8), we can see some particles with a smooth appearance corresponding to a new fractured surface of particles (Fig. 9A) compared to old fractured surface (Fig. 9B). In the case of silty sand sediment (Ss44), SEM micrographs revealed numerous small particles $(0.1-10 \mu \mathrm{m})$ that are agglomerated or aggregated on the surface of larger particles (few tens of microns) (Fig. 9C). In the silt sediment (Ss84), we have occasionally observed some diatoms ( 4 to $40 \mu \mathrm{m}$, porous; Fig. 9D), acicular particles (2 to $50 \mu \mathrm{m}$;

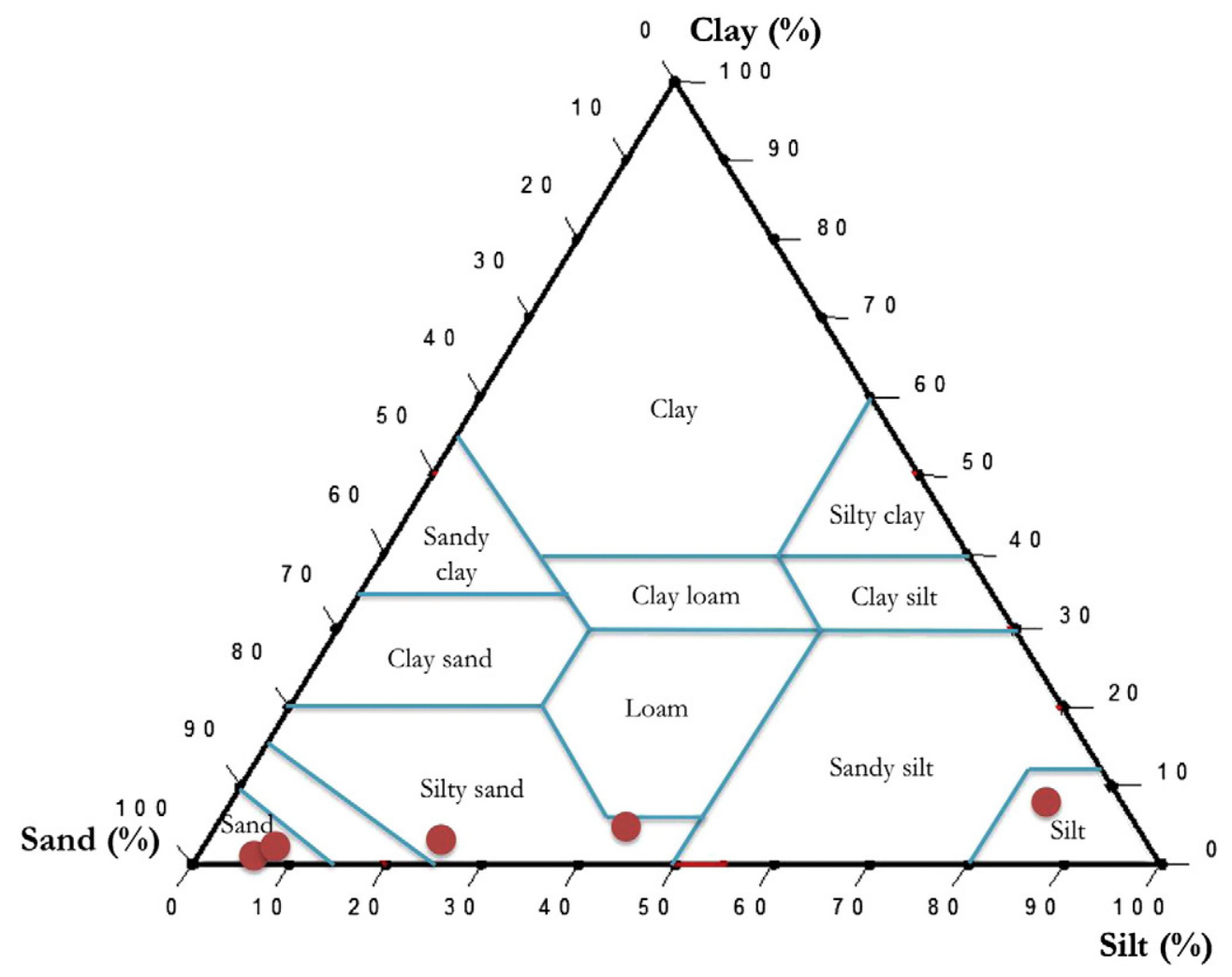

Fig. 8. USDA soil textural triangle for classification of studied sediments. 

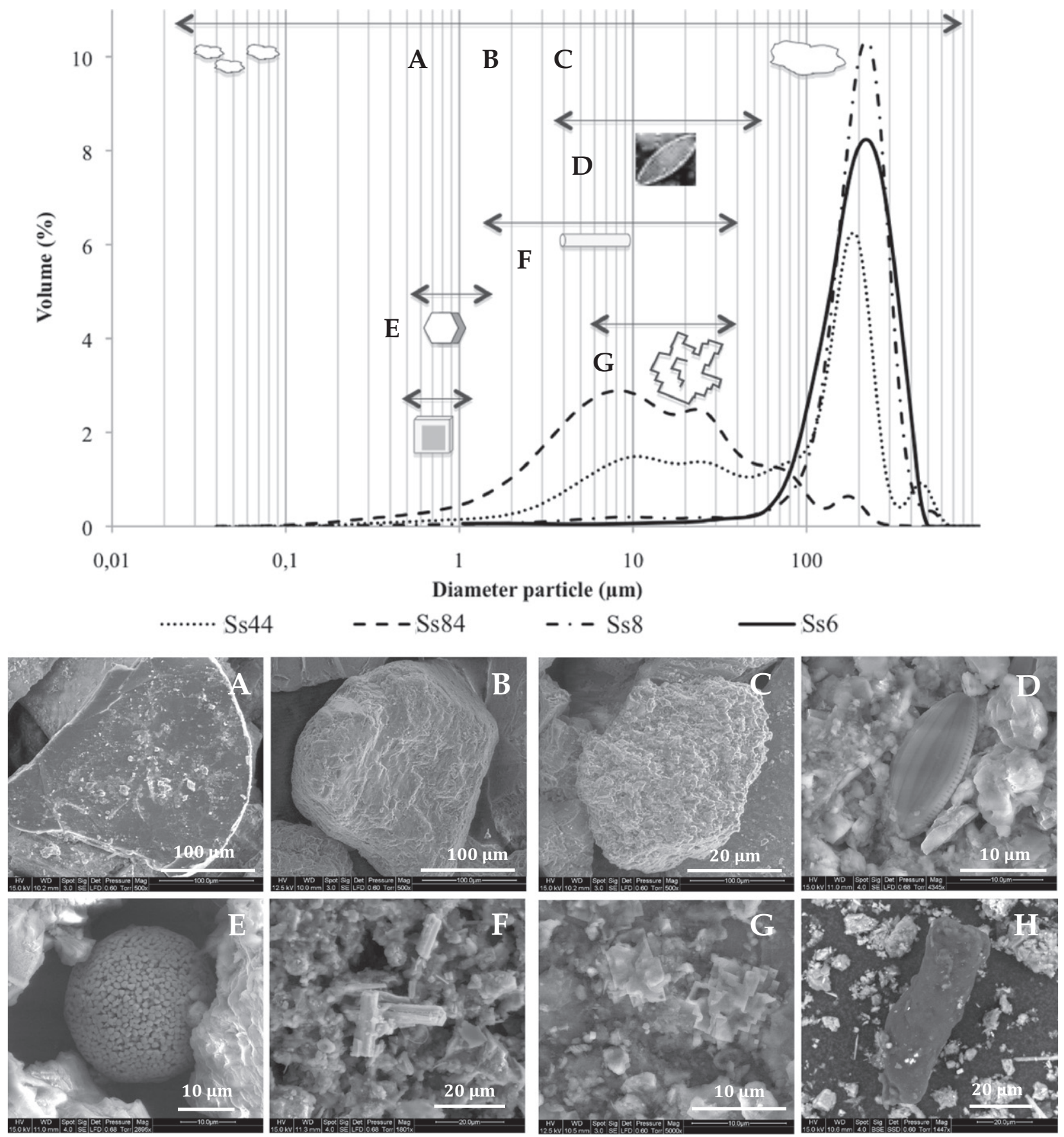

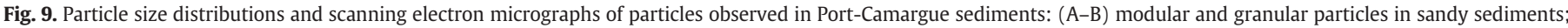
(C) agglomerated particles; (D) diatom; (E) hexagonal particles; (F) acicular particles; (G) crystalline aggregates; (H) particulate organic matter.

$\Psi_{\text {thickness/length }}$ of 0.04 to 0.2 ; Fig. 9 F), cubic crystalline particles (0.8 to $1 \mu \mathrm{m}$; Fig. 9G), and hexagonal particles (0.9 to $1.5 \mu \mathrm{m}$ ), which can form a spherical structure (Fig. 9E). Rarely some particulate organic matters (Fig. 9H) were observed, highlighting that organic matter is mainly molecular (dissolved and/or adsorbed) and not particular.

\subsubsection{Study of agglomeration/dispersion state}

As seen previously on Fig. 9C, studied sediments can present agglomeration behaviour. In dredging framework, agglomeration/ dispersion state of sediments can have an impact on physical and chemical mobilization of particles (Fig. 1.). Firstly, SEM micrographs permitted to observe agglomeration/dispersion state of studied sediments. Secondly, zeta potential values gave information about electrostatic interactions between particles. Moreover, a study was also realized combining laser granulometry and ultrasonic in order to appreciate electrostatic attraction forces.

3.1.5.1. Identification of agglomerates. To observe agglomeration or aggregation state of particles, SEM micrographs were realized on a drop of a much diluted suspension ( 1 vol.\%) in demineralised water [26]. In this work, the particles of size 0.1 to $10 \mu \mathrm{m}$, which comprise large colloidal and fine supracolloidal particles, will be called micronic particles. All images show that micronic particles tend to agglomerate/ aggregate either on large supracolloidal particles (Fig. 10A, named 

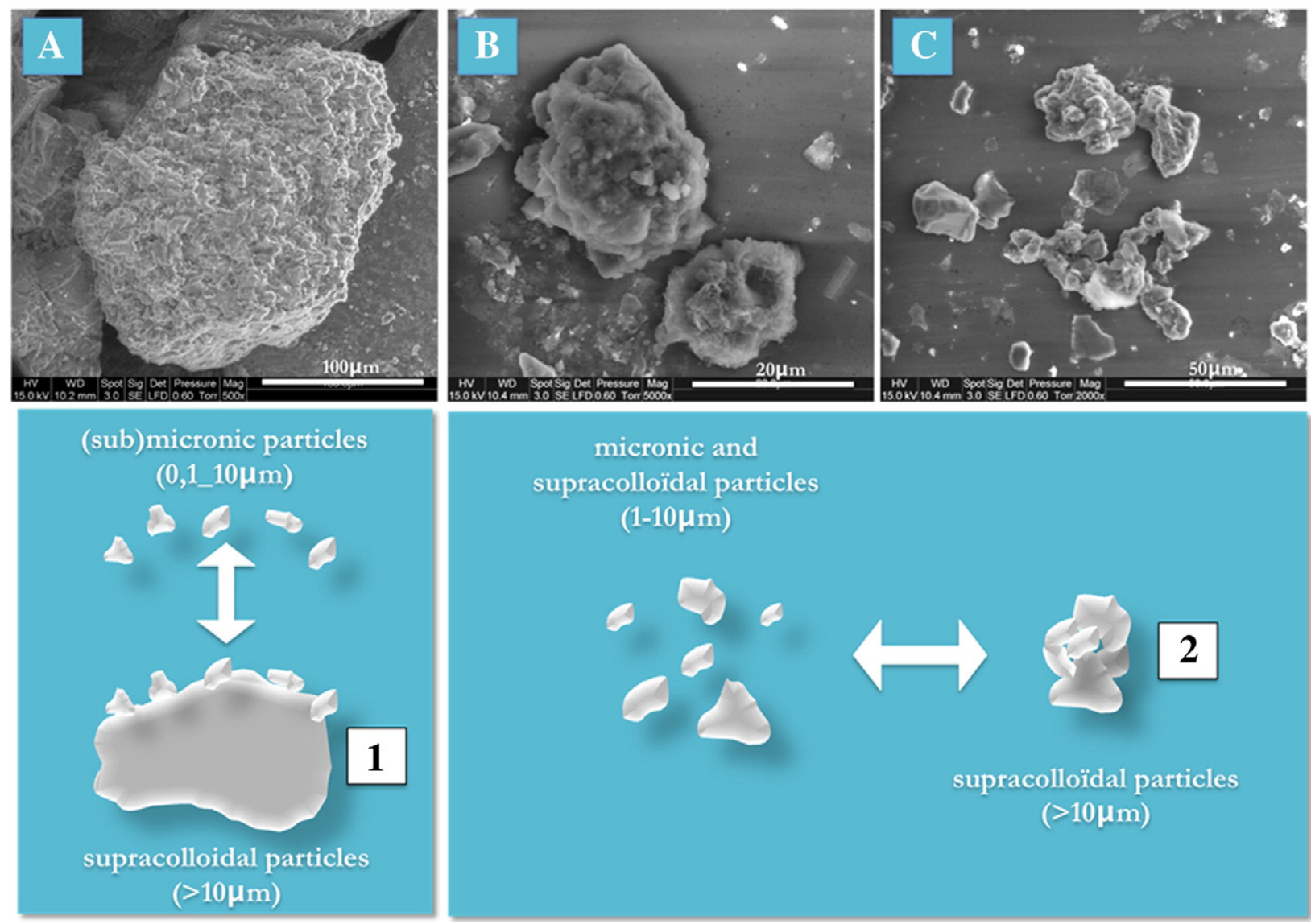

Fig. 10. Identification of agglomerated particles in studied sediments.

agglomerates 1 or together to form larger supracolloidal particles Fig. 10B/C, named agglomerates 2), but few unit particles. However, it would be difficult to differentiate agglomeration and aggregation phenomena.

3.1.5.2. Study of interparticle interaction forces. To provide a better understanding of particle interactions (agglomeration or aggregation), a study was realized combining laser granulometry and ultra-sonification (US). Ultrasonic can break agglomerate bonds modifying particle size distribution. Moreover zeta potential values quantify electrostatic particle interactions. The three sediments taken in the Port-Camargue harbour were investigated (Ss8, Ss44 and Ss84).

Different length of US time (0 to $30 \mathrm{~min}$ ) and different powers (on a scale of 1 to 8 ) of ultra-sonification were used. Between each condition, a particle size distribution was performed and showed on Fig. 11 at $\mathrm{t}=0$ and $10 \mathrm{~min}$ of ultra-sonification (power 4 ). For the three sediments, particle size distributions before and after ultrasound treatment seem to be notably similar. In fact, areas under curve, calculated for sandy $(>80 \mu \mathrm{m})$ and muddy $(<80 \mu \mathrm{m})$ fractions, show a negligible variation of $0.7 \%$ and $0.8 \%$ respectively between estimated areas (percentage expressed in volume). For silty sediment (Ss84) and silty sandy sediment (Ss44), there is no significant impact on textural classification (part 3.1.3). Although, sand sediment (Ss8) presents a greater variation (10.3\%). These results show that time and power of ultra-sonification have no significant impact on particle dispersion. These findings suggest that particles are mainly aggregated or strongly agglomerated. We can note that mud/sand ratio can vary from one sample to another for the same sediment (example Ss44 on Figs. 9 and 11).

Table 4 presents zeta potential values calculated by Smoluchowski treatment (Eq. (2)) from electrophoretic mobility measurements. In literature, we have seen that at high absolute (negative or positive) of zeta potential value, colloidal systems are considered as stable. Indeed, electrostatic repulsions prevent agglomeration of dispersed particles. When the absolute value of zeta potential is low, agglomeration are favoured. Generally, separation between stable and unstable suspensions is taken at $-30 \mathrm{mV}$ or $+30 \mathrm{mV}$ [29]. Measurements carried out in deionised water show negative values of the zeta potential between $-31.9 \mathrm{mV}$ to $-28.9 \mathrm{mV}\left(\mathrm{RSD}_{\max } 4.5 \%\right)$ suggesting that all studied sediments may present a weak agglomeration or a beginning of dispersion behaviour.

\subsection{Granular fraction characterization}

To characterize size fractioned sediments, a granulometric separation is necessary. In order to not disturb the system, dispersion method needs to be in wet conditions and without chemical agents. Our choice fell on a wet sieving. Many authors use wet sieving [23,34,38,39] but granular separation quality doesn't seem to be verified. However, the agglomeration/dispersion phenomena described previously can impact on sediment particle size selection. We can note that in a general case of pollution mobilization studies, results of pollutant chemical analysis may also be influenced.

\subsubsection{Optimisation of separation of granular fractions}

A traditional particle dispersion method was firstly employed: wet sieving used by many authors $[23,34,38,39]$. Fig. 12A presents particle size distributions of different granular fractions of Ss84 $(<20 \mu \mathrm{m}$;

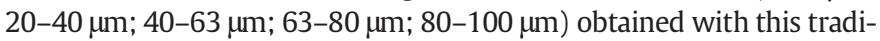
tional method. Results show that each fraction contains many micronic particles $(<10 \mu \mathrm{m})$. Micrograph of $80-100 \mu \mathrm{m}$ fraction shows also 

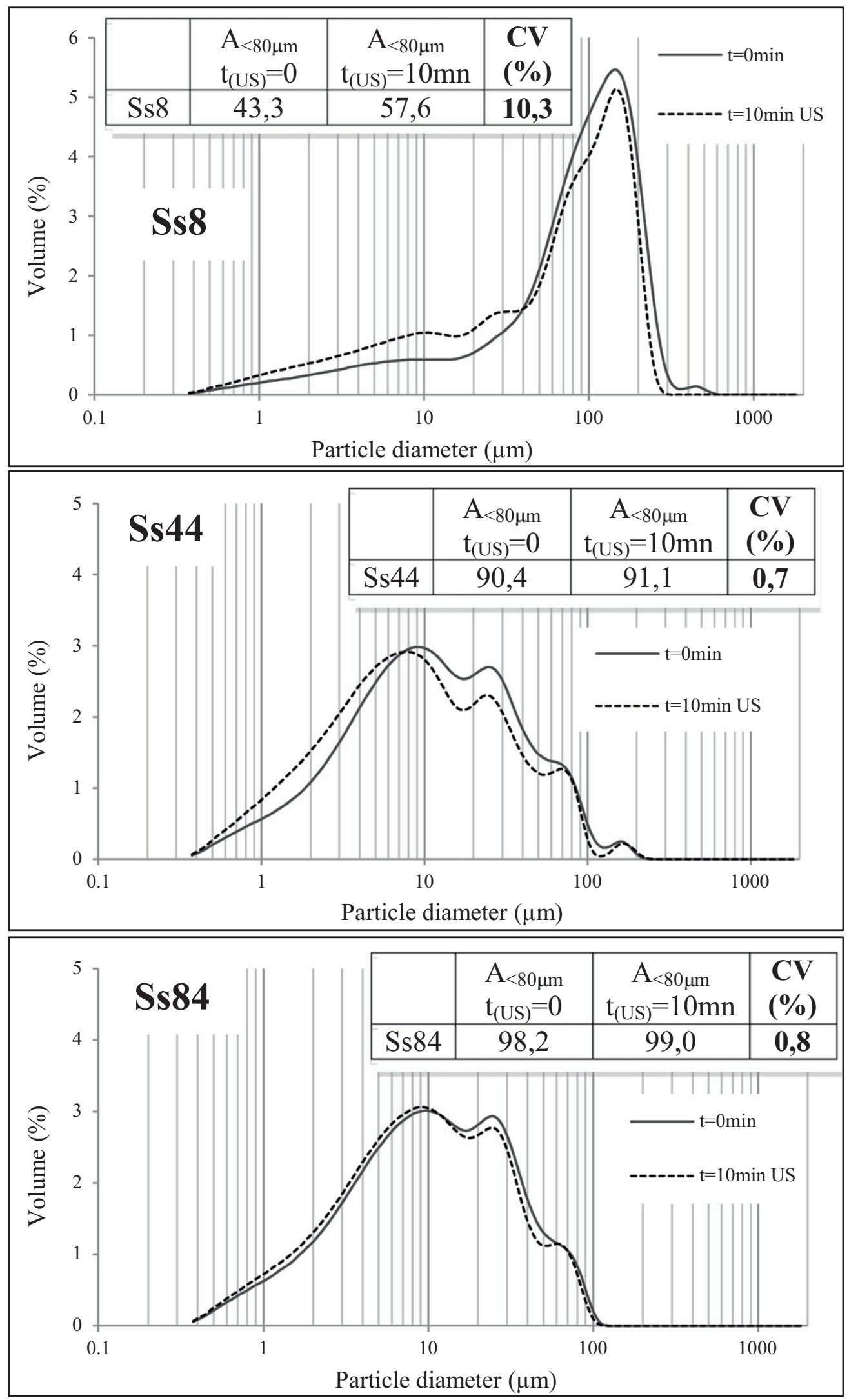

Fig. 11. Impact of ultra-sonification on particle size distribution.

numerous particles of $<80 \mu \mathrm{m}$ size. Particles seem to be mainly agglomerated. This difficulty to disperse particles was observed for all sediment samples and in agreement with results presented in Section 3.1.5.2.
Actually, we noted that sediments lead to clog sieves during selection processing. Previous results identified a weak agglomeration state, but sieve clogging and ultra-sonification study (Section 3.1.5.2) show that 
Table 4

Mobility and zeta potential values of studied sediments.

\begin{tabular}{llll}
\hline Sampling & Electrophoretic mobility $(\mu \mathrm{mcm} / \mathrm{Vs})$ & Zeta potential $(\mathrm{mV})$ & RSD $(\%)$ \\
\hline Ss84 & -2328 & -29.7 & 2.5 \\
Ss44 & -2502 & -31.9 & 1.6 \\
Ss8 & -2267 & -28.9 & 4.5 \\
\hline
\end{tabular}

particle interactions seem to be strong when they exist (US can't break it). To provide a satisfactory dispersion state of sediments, dispersion method must be improved.

Several processes have been investigated as centrifugation, ultrasonication $[21,40]$, rinsing and stirring. Mechanical stirring (providing shear and friction stress) and rinsing with demineralised water were the most effective methods in order to disperse particles in all sediment samples. The developed method consists of getting sediment suspension (described in Section 2.2.1.) through sieves with a mechanical stirring in each sieve. Then, sieves have been rinsed with demineralised water (twice the initial volume used to realize the suspension, i.e. 20 volumes of water to 1 volume of sediment). Fig. 12A and B shows that this optimized method allows a better separation of size fraction link to effective particle dispersion. Phenomena observed in this study highlight the importance to verify separation quality for all studies concerning this scientific area.

\subsubsection{Granular and physicochemical characteristics of sediments}

Scanning Electron Microscopy was realized for each fraction in order to observe particles and their surface after an efficient particle size separation process (Fig. 13). In each size fractioned of sediment, particle surfaces are exempt of fine agglomerate particles. Particle shape is granular, for all sediments. We can also observe that $<20 \mu \mathrm{m}$ fraction contains many agglomerates or aggregates, indicating that fine particles reagglomerate together (agglomerates identified as type 2 in Section 3.1.5.1), according to the zeta potential values.

Secondly, mass percent of size fractions has been determined by difference in mass weighed before and after drying (Table 5). Results show that sandy sediments (Ss6 and Ss8) contain many sandy particles $(>80 \mu \mathrm{m})$, and very few fine particles $(<20 \mu \mathrm{m})$. Silty sand sediment (Ss44) and silt sediment (Ss84) mainly contain $>80 \mu \mathrm{m}$ and $<63 \mu \mathrm{m}$ particles. These results are compared with textural classification of sediment samples described in Section 3.1.3. For all sampling fractions, composition is similar except for proportions of $>80 \mu \mathrm{m}$ particles in Ss84 (silt). This difference may be due to several factors as material heterogeneity and sedimentation of decantable particle $(>100 \mu \mathrm{m})$ in analysis cell of laser granulometer. BET specific areas observed in Section 3.1.2 for bulk sediments are correlated to these results (Fig. 14), especially the $<20 \mu \mathrm{m}$ fraction that is very studied in pollution issues. Results show that there is few or no $<20 \mu \mathrm{m}$ particles in the fractions $20-40 \mu \mathrm{m}, 40-63 \mu \mathrm{m}, 63-80 \mu \mathrm{m}$ and $>80 \mu \mathrm{m}$.

As with bulk sediments, mineralogical analyses and density (Table 6) of sediment fractions show that they have a similar mineralogical composition.

\section{Conclusion}

An exhaustive physico-chemical and morpho-granular characterization of sediments collected in Port-Camargue harbour has been investigated to study their granular properties and agglomeration/dispersion state. In dredging framework, particle organisation state could lead to disperse pollution not only by chemical mobilization but also by physical mobilization (due to fine particle behaviour), leading to take pollution away from harbour. Therefore, this work focuses on particle solid phase of sediment, and especially muddy fraction $(<80 \mu \mathrm{m})$.

Firstly, the composition and physicochemical properties are determined for the bulk sediments and their granular fractions. Three studied sediments, compared to a sample of sand, are characterized by their mineralogical composition of lithogenic and biogenic origin, dominated by quartz, calcite and feldspars, as most of marine sediments.

Moreover, an exhaustive granular characterization is realized, and shows that sediments of Port-Camargue present different particle size distributions but are on average fine $(<300 \mu \mathrm{m})$. An exhaustive identification of granular populations shows that they are very complex matrices with many granular and mineral particles and very few organic particles. Studied granular properties (specific area and particle size) highlight complex state of particle organisation with roughness surface and agglomeration phenomena that can contribute to trap pollutants and water in these systems. Two types of agglomerates are observed: agglomeration of micronic particles $(<10 \mu \mathrm{m})$ and agglomeration of micronic particles on large supracolloidal surfaces. This approach also permits classification of marine sediments in function of their textural

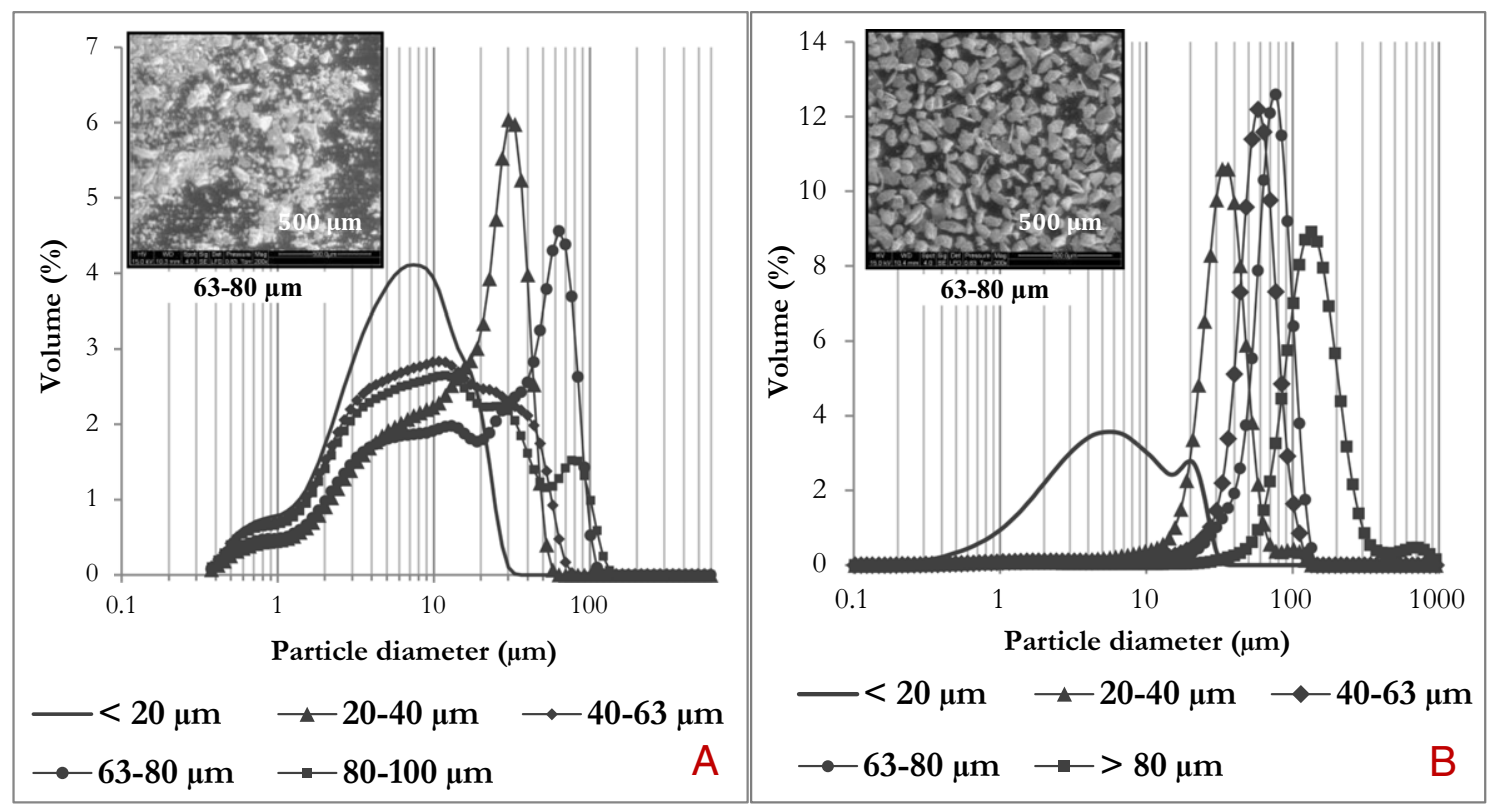

Fig. 12. Fraction particle size distributions and scanning electron micrograph of 63-80 $\mu \mathrm{m}$ fraction (Ss84) obtained with A) traditional wet sieving; B) stirred sieving and rinsing. 


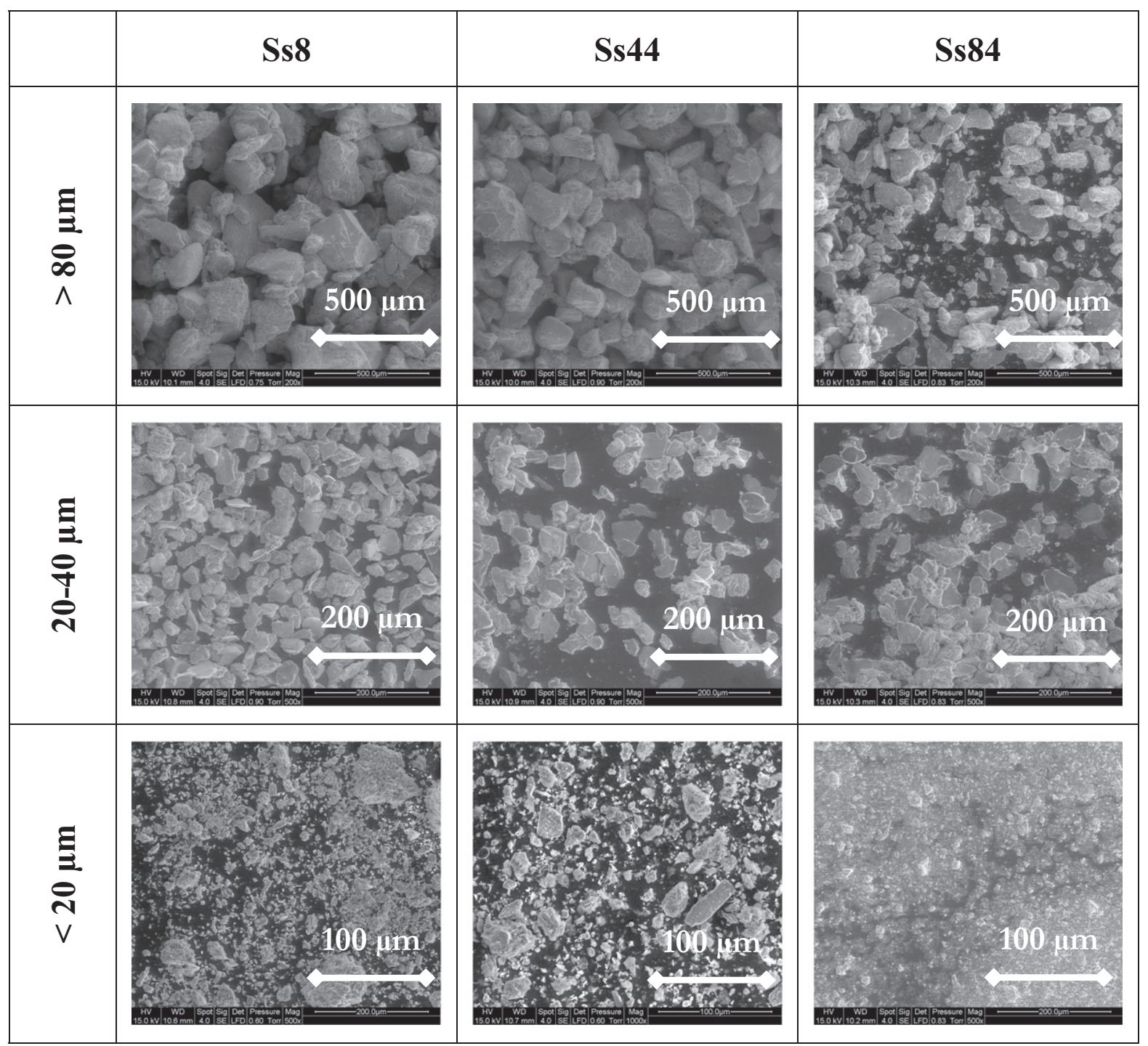

Fig. 13. SEM micrographs illustrating the main features of some granular fractions.

aspects or their particle size distribution and silt percentage: Ss84 (silt), Ss44 (silty sand), Ss8 and Ss6 (sand).

To characterize size fractioned sediments, an optimized particle size selection is necessary because studied agglomeration/dispersion phenomena impacted this process (clogging). These phenomena are due to zeta potential value close to $-30 \mathrm{mV}$ which corresponds to the limit between weak agglomeration and nascent dispersion state. An ineffective dispersion can also lead to physical mobilization by matter transfer between granular fractions. Thus depending on dispersion state of sediment, a pollutant (particle or molecule) may occur in one fraction or another. Mechanical stirring, providing shear and friction stress, and rinsing with demineralised water are the most effective methods in order to disperse the particles in all sediment samples. The observed phenomena highlight the importance to verify separation quality.

Table 5

Mass percent fraction (\%) in studied sediments.

\begin{tabular}{llllll}
\hline \multirow{2}{*}{ Sampling } & \multicolumn{5}{l}{ Mass percent fraction (\%) } \\
\cline { 2 - 6 } & $>80 \mu \mathrm{m}$ & $63-80 \mu \mathrm{m}$ & $40-63 \mu \mathrm{m}$ & $20-40 \mu \mathrm{m}$ & $<20 \mu \mathrm{m}$ \\
\hline Ss84 & 44 & 4 & 10 & 9 & 33 \\
Ss44 & 55 & 2 & 6 & 9 & 28 \\
Ss8 & 85 & 2 & 2 & 2 & 10 \\
Ss6 & 100 & 0 & 0 & 0 & 0 \\
\hline
\end{tabular}

This interdisciplinary work oriented towards the morphogranulometric aspects of particle solid phase of marine sediments can supplement and enrich the chemical, physicochemical and biological approaches observed usually in sediment researches. Finally, the simultaneous use of laser granulometry and SEM proves to be an effective strategy for investigating the granular properties and particle interactions showing application in global pollution mobilization studies.

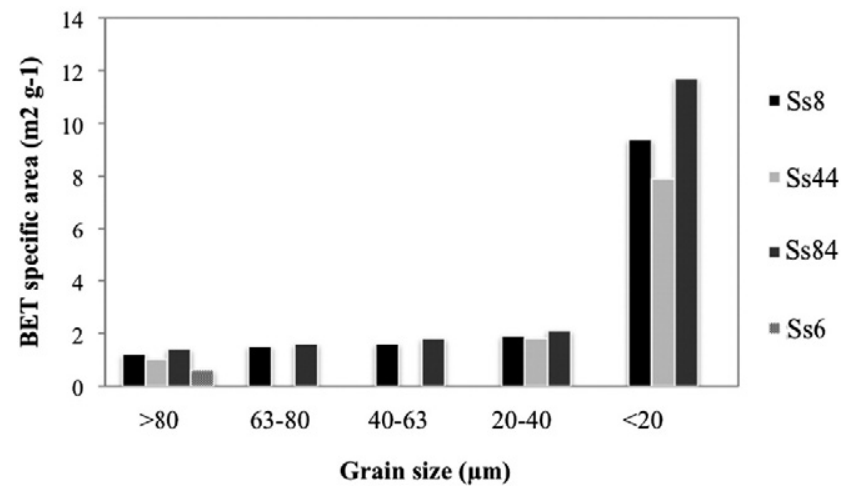

Fig. 14. Evolution of BET specific areas in function of granular fractions with optimized sieving. 
Table 6

Density of sediment granular fractions.

\begin{tabular}{lll}
\hline Sampling & Density & \\
\cline { 2 - 3 } & $>80 \mu \mathrm{m}$ & $<20 \mu \mathrm{m}$ \\
\hline Ss84 & 2.69 & 2.65 \\
Ss44 & 2.68 & 2.66 \\
Ss8 & 2.68 & 2.67 \\
\hline
\end{tabular}

\section{Acknowledgements}

This work was carried out in framework of the ECODREDGE project, financed by FUI (Fonds Unique Interministériel $n^{\circ}$ F1106008 J) from France. The authors would like to thank the Port-Camargue Master's Office for management of ECODREDGE-MED project and their assistance during the sampling. We are also grateful to Jean-Marie Taulemesse (C2MA-Ecole des Mines d'Alès) for his assistance in obtaining scanning electron micrographs.

\section{References}

[1] C. Alzieu, Dragages et environnement marin - Etat des connaissances, IFREMER, 1999. (209 pp).

[2] J.S. Latimer, W.R. Davis, D.J. Keith, Mobilization of PAHs and PCBs from in-place contaminated marine sediments during simulated resuspension events, Estuar. Coast. Shelf Sci. 49 (1999) 577-595.

[3] P. Erftemeijer, R.R. Lewis, Environmental impacts of dredging on seagrasses: a review, Mar. Pollut. Bull. 52 (2006) 1553-1572.

[4] K. McMahon, P.S. Lavery, M. Mulligan, Recovery from the impact of light reduction on the seagrass Amphibolis griffithii, insights for dredging management, Mar. Pollut. Bull. 62 (2011) 270-283.

[5] D.A. Roberts, Causes and ecological effects of resuspended contaminated sediments (RCS) in marine environments, Environ. Int. 40 (2012) 230-243.

[6] R. Boutin, Dragage et rejets en mer. Les produits de type vase, Presses de l'Ecole Nationale des Ponts et Chaussées, 3072000.

[7] J. Eggleton, K.V. Thomas, A review of factors affecting the release and bioavailability of contaminants during sediment disturbance events, Environ. Int. (2004) 973-980.

[8] L.M. Mayer, M.L. Wells, Aggregation of colloids in estuaries, Reference Module in Earth Systems and Environmental Sciences, From Treatise on Estuarine and Coastal Science, 42011. 143-160.

[9] W. Stumm, Aquatic colloids as chemical reactants: surface structure and reactivity, Colloids Surf. A Physicochem. Eng. Asp. (1993) 1-18.

[10] L. Sigg, P. Behra, W. Stumm, Chimie des milieux aquatiques - Chimie des eaux naturelles et des interfaces dans l'environnement, Third edition Dunod, 2000. (567 pp).

[11] R.C. Grabowski, I.G. Droppo, G. Wharton, Erodibility of cohesive sediment: the importance of sediment properties, Earth Sci. Rev. 105 (2011) 101-120.

[12] P. Baumard, H. Budzinski, Q. Michon, P. Garrigues, T. Burgeot, J. Bellocq, Origin and bioavailability of PAHs in the Mediterranean Sea from mussel and sediment records, Estuar. Coast. Shelf Sci. 47 (1998) 77-90.

[13] G. De Luca, A. Furesi, R. Leardi, G. Micera, A. Panzanelli, P. Piu, G. Sanna, Polycyclic aromatic hydrocarbons assessment in the sediments of the Porto Torres Harbor (Northern Sardinia, Italy), Mar. Chem. 86 (2004) 15-32.

[14] S. Galanopoulou, A. Vgenopoulos, N. Conispoliatis, DDTs and other chlorinated organic pesticides and polychlorinated biphenyls pollution in the surface sediments of Keratsini harbour, Saronikos gulf, Greece, Mar. Pollut. Bull. 50 (2005) 520-525.

[15] E. Huntingford, A. Turner, Trace metals in harbor and slipway sediments from the island of Malta, central Mediterranean, Mar. Pollut. Bull. 62 (2011) 1557-1561.
[16] Y. Mamindy-Pajany, C. Hurel, F. Géret, F. Galgani, F. Battaglia-Brunet, N. Marmier, M. Romeo, Arsenic in marine sediments from French Mediterranean ports: geochemical partioning, bioavailability and ecotoxicology, Chemosphere 90 (2013) 2730-2736.

[17] N. Warren, I.J. Allan, J.E Carter, W.A. House, A. Parker, Pesticides and other microorganic contaminants in freshwater sedimentary environments - a review, Appl. Geochem. 18 (2003) 159-194.

[18] J.J. Pignatello, Soil organic matter as a nanoporous sorbent of organic pollutants, Adv. Colloid Interf. Sci. 76-77 (1998) 445-467.

[19] X. Capilla, C. Schwartz, J.-P. Bedell, T. Sterckeman, Y. Perrodin, J.-L. Morel, Physicochemical and biological characterization of different dredged sediment deposit sites in France, Environ. Pollut. 143 (2006) 106-116.

[20] V. Roussiez, W. Ludwig, A. Monaco, J.-L. Probst, I. Bouloubassi, R. Buscail, G. Saragoni, Sources and sinks of sediment-bound contaminants in the Gulf of Lions (NW Mediterranean Sea): a multi-tracer approach, Cont. Shelf Res. 26 (2006) 1843-1857.

[21] Q. Huang, F. Li, R.X.Q. Wang, W. Tan, Characterization of organo-mineral aggregates of chernozem in northeast China and their adsorption behavior to phenanthrene, Soil Chem. 72 (2008) 362-369.

[22] S. Orecchio, M.R. Mannino, Chemical speciation of polycyclic aromatic hydrocarbons in sediments: partitioning and extraction of humic substances, Mar. Pollut. Bull. 60 (2010) 1175-1181.

[23] E.S. Carol, E.E. Kruse, E.L. Tavani, Physicochemical characterization of sediments from the coastal wetland of Samborombon Bay, Argentina, J. S. Am. Earth Sci. (2012) 26-32.

[24] P.R. Owens, E.M. Rutledge, Morphology, Encyclopaedia of Soils in the Environment, 2005. 511-520.

[25] D. Grosdemange, Guide pour la gestion des opérations de dragage, Vivo Environnement, Fédération Française des Ports de Plaisance, 2005 (82 p.).

[26] C. Autier, N. Azema, J.-M. Taulemesse, L. Clerc, Mesostructure evolution of cement pastes with addition of superplasticizers highlighted by dispersion indices, Powder Technol. 249 (2013) 282-289.

[27] T. Tadros, Dispersion of Powders in Liquids and Stabilization of Suspensions, Wiley-VCH, 2012, ISBN 978-3-527-32941-0.

[28] D. Lerche, T. Sobisch, Evaluation of particle interactions by in situ visualization of separation behaviour, Colloids Surf. A Physicochem. Eng. Asp. 440 (2013) 120-130.

[29] S. Pollastri, A.F. Gualtieri, M.L. Gualtieri, M. Hanuskova, A. Cavallo, G. Gaudino, The Zeta potential of mineral fibres, J. Hazard. Mater. 276 (2014) 469-479.

[30] Y.H. Li, J.E. Schoonmaker, Chemical composition and mineralogy of marine sediments, Second Edition, Reference Module in Earth Systems and Environmental Sciences, From Treatise on Geochemistry, 7, 2005. 1-35.

[31] D. Heap Andrew, L. Sbaffi, Composition and distribution of seabed and suspended sediments in north and central Torres Strait, Australia, Cont. Shelf Res. 28 (2008) 2174-2187.

[32] R.T. Wilkin, H.L. Barnes, Formation processes of framboidal pyrite, Geochim. Cosmochim. Acta 61 (1997) 323-339.

[33] C.-L. Chou, Sulfur in coals: a review of geochemistry and origins, Int. J. Coal Geol. 100 (2012) 1-13.

[34] T.A. Fontaine, T.D. Moore, B. Burgoa, Distributions of contaminant concentration and particle size in fluvial sediment, Water Res. 34 (2000) 3473-3477.

[35] N. Romano, A. Santini, Effectiveness of using pedo-transfer functions to quantify the spatial variability of soil water retention characteristics, J. Hydrol. 202 (1997) 137-157.

[36] K.M. Banat, F.M. Howari, A.A. Al-Hamad, Heavy metals in urban soils of central Jordan: should we worry about their environmental risks? Environ. Res. 97 (2005) 258-273.

[37] X. Luo, S. Yu, X. Li, Distribution, availability, and sources of trace metals in different particle size fractions of urban in Hong Kong: implications for assessing the risk to human health, Environ. Pollut. 159 (2011) 1317-1326.

[38] C.A. Thimsen, R.G. Keil, Potential interactions between sedimentary dissolved organic matter and mineral surfaces, Mar. Chem. 62 (1998) 65-76.

[39] X.-C. Wang, Y.-X. Zhang, R.F. Chen, Distribution and partitioning of polycyclic aromatic hydrocarbons (PAHs) in different size fractions in sediments from Boston Harbor, United States, Mar. Pollut. Bull. 42 (2001) 1139-1149.

[40] A.P. Edwards, J.M. Bremner, Dispersion of soil particles by sonic vibration, J. Soil Sci. 18 (1967) 1. 